\title{
EVALUACIÓN IN VITRO DE LA EFICACIA DEL DIGLUCONATO DE CLORHEXIDINA EN GEL AL 0,2\% Y 2\% COMO MEDICACIÓN INTRACONDUCTO FRENTE A Candida albicans
}

\author{
${ }^{1}$ Martha Patricia Verjel Bonza, ${ }^{1}$ Vanesa Martínez Chacón, ${ }^{1}$ Beatriz Estela Duarte Pérez, \\ ${ }^{2}$ Laura Viviana Herrera Sandoval, ${ }^{3}$ Martha Elena Varón Plata, ${ }^{4}$ Anderson Bermón Angarita, \\ ${ }^{5}$ Luis Jesús Cantillo Silva \\ ${ }^{1}$ Estudiante de II año Especialización en Endodoncia U. Santo Tomás, Colombia. \\ ${ }^{2}$ Bacteriologa y Laboratorista Clínico U. Industrial de Santander, Magíster en Ciencias Básicas Biomédicas U. Industrial de Santander, Docente U. Santo Tomás, Colombia. \\ ${ }^{3}$ Odontóloga, Especialista en Endodoncia U. Santo Tomás, Docente U. Santo Tomás, Colombia. \\ ${ }^{4}$ Médico U. de Antioquia, Magíster en Epidemiología U. CES, Epidemiólogo Fundación Cardiovascular de Colombia, Colombia. \\ ${ }^{5}$ Odontólogo U. Nacional, Especialista Docencia Universitaria, Docente U. Santo Tomás, Colombia.
}

Autor responsable de correspondencia: Martha Patricia Verjel Bonza

Correo electrónico: marpaver@hotmail.com

\section{RESUMEN}

Objetivo: evaluar la eficacia del digluconato de clorhexidina en gel al 0,2\% y 2\% cuando es utilizado como medicación intraconducto en raíces de dientes humanos extraídos que han sido contaminados con Candida albicans.

Materiales y métodos: estudio experimental In vitro en el que se emplearon 48 raíces de dientes unirradiculares las cuales fueron instrumentadas con técnica convencional hasta la lima K número 40, para ser inoculadas con Candida albicans ATCC60193 durante 72 horas. Las muestras fueron distribuidas en tres grupos de 16 especímenes cada uno para la medicación intraconducto con digluconato de clorhexidina al $0,2 \%$, digluconato de clorhexidina al $2 \%$ y solución salina al $0,9 \%$, durante siete días. Posteriormente, cada especímen fue instrumentado con lima K número 40 para obtener el barrillo dentinario y cultivarlo en agar Sabouraud $2 \%$ durante 48 horas a $37^{\circ} \mathrm{C}$ para determinar las Unidades Formadoras de Colonias por $\mathrm{mL}$ (UFC/mL) de esta levadura.

Resultados: el modelo In vitro permitió establecer el crecimiento de Candida albicans, en el interior del conducto en $100 \%$ en las raíces de los dientes antes de la medicación intraconducto. Se encontró una diferencia estadísticamente significativa entre el grupo tratado con solución salina al $0,9 \%$ con respecto a los grupos de clorhexidina al $0,2 \%$ y al $2 \%$. No se observó una diferencia estadísticamente significativa en las UFC/mL entre los grupos tratados con clorhexidina al $0,2 \%$ y al $2 \%$.

Conclusiones: el digluconato de clorhexidina en gel al 0,2\% y $2 \%$, como medicación intraconducto disminuyó las UFC/mL de Candida albicans después de siete días. [Verjel MP, Martínez V, Duarte BE, Herrera LV, Varón ME, Bermón A, Cantillo LJ. Evaluación In vitro de la eficacia del digluconato de clorhexidina en gel al 0,2\% y $2 \%$ como medicación intraconducto frente a Candida albicans. Ustasalud 2013; 12: 83 - 90]

Palabras claves: Candida albicans, Clorhexidina, Actividad antimicrobiana.

\section{IN VITRO EVALUATION OF THE EFFECTIVENESS OF CHLORHEXIDINE DIGLUCONATE GEL 0.2\% AND 2\% AS AN INTRACANAL MEDICATION AGAINST Candida albicans}

\begin{abstract}
Objective: to assess the efficacy of chlorhexidine digluconate gel $0.2 \%$ and $2 \%$ used as intracanal medicaments against Candida albicans in roots of extracted human teeth

Methods: an experimental In vitro study was done. The sample consisted in 48 single-rooted roots, which were instrumented with conventional technique to No. $40 \mathrm{~K}$ file and then they were inoculated with Candida albicans ATCC60193 for 72 hours. The samples were divided into three groups of 16 specimens each for intracanal medication with chlorhexidine digluconate $2 \%$ chlorhexidine digluconate $0.2 \%$ and $0.9 \%$ saline solution for seven days. After that each specimen was instrumented again with $\mathrm{K}$-file number 40 to obtain the smear layer of the root canal system to be cultivated in $2 \%$ agar Sabouraud for 72 hours at $37^{\circ} \mathrm{C}$ to determine the Count Forming Units per $\mathrm{mL}(\mathrm{CFU} / \mathrm{mL})$ of Candida albicans.

Results: the model of this study allowed to establish that Candida albicans grew in all the root canals of the teeth before before the intracanal medication was injected. It was found that group three (treated with $0.9 \%$ saline solution) showed a statically significant difference with respect to the other two groups, chlorhexidine $2 \%$ and clorhexidine $0.2 \%$. The Mann-Whitney U test also showed no significant differences in the $\mathrm{CFU} / \mathrm{mL}$ in the two clorhexidine treated groups, the one with $0,2 \%$ and the one with $2 \%$.

Conclusion: chlorhexidine digluconate gel $0.2 \%$ and $2 \%$, as intracanal medication, significantly decreased CFU/mL of Candida albicans, but is not completely destroyed after a period of seven days.
\end{abstract}

Key words: Candida albicans, Chlorhexidine digluconate, Antimicrobial activity.

Recibido para publicación: febrero 17 de 2013. Aceptado para publicación: septiembre 20 de 2013. 


\section{INTRODUCCIÓN}

Los microorganismos son reconocidos como los agentes etiológicos de la mayoría de las enfermedades pulpares y perirradiculares. Aunque las bacterias han sido las más estudiadas, los hongos también están asociados con conductos radiculares infectados. Algunos autores han observado o cultivado hongos de infecciones endodónticas y se ha asociado la presencia de los mismos con infecciones endodónticas resistentes a la terapia. ${ }^{1}$

Los conductos radiculares de dientes infectados tienen una flora microbiana compleja que consta de cocos, bacilos, espiroquetas, filamentos y algunas veces hongos. ${ }^{2}$ La presencia de levaduras en conductos radiculares infectados ha mostrado una incidencia que varía entre $7 \%$ a $55 \%$. $^{3}$

Casi todas las levaduras aisladas pertenecen al género Candida siendo la especie albicans la más común. Así mismo, ha sido referido como el microorganismo endodóntico más resistente In vitro a la terapia de hidróxido de calcio; esto en parte puede explicar la presencia de las mismas en caso de una periodontitis apical persistente. ${ }^{4,5}$

El hidróxido de calcio, ya sea como una suspensión pura en agua destilada o en varias soluciones salinas, es un medicamento comúnmente utilizado en el conducto radicular, efectivo sobre la mayoría de los microorganismos aislados de conductos radiculares infectados pero no en el caso de Candida albicans. ${ }^{6}$ En respuesta a la eficacia ambivalente del hidróxido de calcio, la clorhexidina se ha sugerido como un medicamento intraconducto que puede ser llevado en una variedad de vehículos. ${ }^{7-10}$

Candida albicans es un patógeno muy versátil; esta propiedad está relacionada con su capacidad de sobrevivir como comensal aún en situaciones fisiológicas extremas como en $\mathrm{pH}$ elevados. Tiene moléculas de superficie y puede coagregarse sobre todo con Streptococcus viridans. Sus enzimas hidrolíticas están involucradas en el daño del tejido perirradicular y las colagenolíticas degradan el colágeno de la dentina y lo convierten en su sustrato. Tiene la habilidad para formar biofilm lo que hace que sea más patógeno porque el medicamento penetra las capas más superficiales y las más profundas quedan intactas. ${ }^{9}$

Resultados de estudios clínicos han mostrado que al menos el 50\% de los conductos radiculares retienen microorganismos después de los procedimientos endodónticos basados en protocolos con hipoclorito de sodio o clorhexidina, ${ }^{10}$ lo que hace necesario la medicación en caso de conductos radiculares infectados.
La clorhexidina es una biguanida catiónica que es capaz de atravesar la pared celular o membrana externa presumiblemente por difusión pasiva y subsecuentemente ataca el citoplasma bacteriano o membrana interna. ${ }^{11} \mathrm{~A}$ bajas concentraciones la clorhexidina es bacteriostático; sin embargo, en altas concentraciones induce la precipitación o coagulación de los elementos intracelulares resultando en efecto bactericida. ${ }^{12}$ En adición a su efecto antimicrobiano inmediato, la clorhexidina puede ser absorbida por el tejido dental proporcionando una actividad de sustantividad. ${ }^{13,14}$ El digluconato de clorhexidina ha sido recomendado como irrigante del conducto radicular y algunos estudios han demostrado además de su sustantividad, su amplio espectro de acción antimicrobiana y bajo grado de toxicidad. En endodoncia su aplicación en forma de gel ha sido sugerida, pero solamente como medicación intraconducto. ${ }^{15}$

Este estudio utilizó un modelo In vitro para evaluar la eficacia de la medicación intraconducto frente a Candida albicans, para lograr tal propósito se utilizó el digluconato de clorhexidina en gel en concentración al $0,2 \%$ y $2 \%$ durante siete días y se constató mediante el análisis del barrillo dentinario obtenido con lima $\mathrm{K}$ número 40 , una disminución del número de Unidades Formadoras de Colonias por $\mathrm{mL}(\mathrm{UFC} / \mathrm{mL})$ de esta levadura al compararlas con el conteo de UFC/mL del grupo control; demostrando que sí hay diferencia estadísticamente significativa.

\section{MATERIALES Y MÉTODOS}

Recolección de dientes: los dientes utilizados en el estudio fueron recolectados en diferentes centros clínicos de Bucaramanga y su área metropolitana. Se incluyeron piezas dentales extraídas por diferentes causas diagnósticas y con acta de donación del paciente. Posteriormente, los dientes fueron limpiados con papel absorbente para retirar los residuos de tejido conectivo; se les realizó un enjuague por 24 horas en agua estéril y se introdujeron en recipientes que contenían formalina al $10 \%$ con el fin de preservarlos de la deshidratación y contaminación externa. ${ }^{6}$

Selección de dientes y raíces: este procedimiento fue realizado por los investigadores en el Laboratorio de Investigación y Ciencias Básicas de la Universidad Santo Tomás, sede Floridablanca.

Se realizó la estandarización de la longitud radicular (16 mm) con la ayuda de un dentimetro, lima y lápiz marcador al tener como limite cervical la unión amelocementaria a nivel coronal y en el tercio apical, el ápice radicular. Luego se procedió a realizar la remoción de la corona del diente en la 
unión cemento esmalte para lo cual se utilizó un mandril y disco delgado de carburo. Los dientes fueron refrigerados por inmersión en agua fría para evitar lesionar la estructura dentaria generada por el calor excesivo. Al concluir la remoción de la corona de los 48 dientes, las raíces fueron introducidas en un frasco de vidrio que contenía agua destilada. ${ }^{6}$

Preparación quimiomecánica de las raíces: se amplió el tercio cervical de las raíces, con ayuda de un micromotor y fresas Gates Glidden No. 2 y 3 para permitir un mejor acceso a los conductos. La Preparación Quimiomecánica (PQMC) de los conductos se realizó con una técnica convencional de preparación de conductos con movimientos de limado de la pared dentinal. Se continuó la PQMC con limas K de la primera serie $1 \mathrm{~mm}$ antes del ápice $(15 \mathrm{~mm})$ hasta la lima No. 40, se irrigó entre lima y lima con $2 \mathrm{ml}$ de solución salina llevada en jeringa (Endoject) con un calibre de aguja No. 27.

Remoción del barrillo dentinario: la remoción del barrillo dentinario del interior del conducto se realizó con $2 \mathrm{~mL}$ de ácido cítrico al $10 \%$ y este fue removido a su vez con $5 \mathrm{~mL}$ de solución salina. ${ }^{6,9}$

Secado del conducto: los conductos se secaron con conos de papel estéril No. 35 y 40. La limpieza y secado exterior de las raíces se realizó con agua destilada y papel absorbente. Se procedió al recubrimiento externo de las raíces $2 \mathrm{~mm}$ antes del extremo cervical de la raíz y la totalidad del tercio medio y apical, mediante el pincelado (pincel para uñas) de una primera capa de resina epóxica. Luego del secado, se realizó una segunda aplicación con la misma resina.

Esterilización e inoculación de Candida albicans: las piezas se llevaron con una pinza algodonera a un tubo de ensayo con tapa de rosca y fueron sumergidas en $10 \mathrm{~mL}$ de solución estéril de caldo tripticasa soya $\left(\right.$ Merck $\left.^{\circledR}\right)$ para ser llevados al autoclave durante 30 minutos a $121^{\circ} \mathrm{C}$ (Figura 1). Posteriormente, la esterilidad de las raíces fue verificada a través de la ausencia de turbidez luego de 24 horas de incubación a $37^{\circ} \mathrm{C}$.

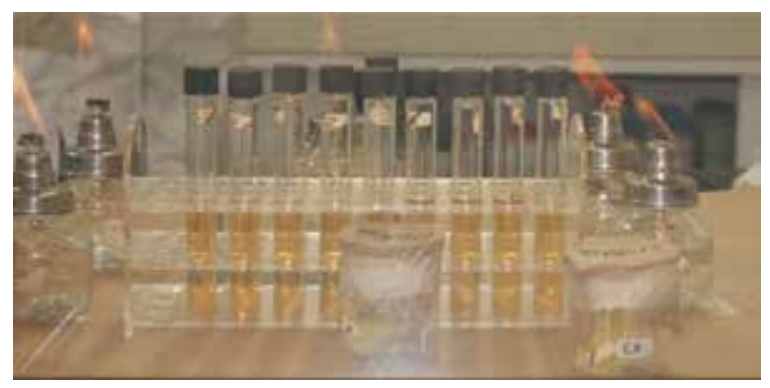

Figura 1. Confirmación de la esterilización de las raíces.
Para la inoculación se realizó un subcultivo de $C$. albicans en agar Sabouraud 2\% (Merck ${ }^{\circledR}$ ), con 48 horas de incubación a $37{ }^{\circ} \mathrm{C}$. A partir de este se preparó una suspensión celular en caldo tripticasa soya $\left(\right.$ Merck $^{\circledR}$ ) ajustada a la escala McFarland 0,5 para asegurar una cantidad de levaduras de $10^{8}$ Unidades Formadoras de Colonias por mililitro (UFC/mL).

Bajo medidas de bioseguridad, en un ambiente estéril (mecheros con alcohol industrial 98\%) se sacaron las raíces de los dientes de los tubos de ensayo y se tomaron con una placa de parafina estéril $(4 \times 2 \mathrm{~cm})$ (Figura 2). Se secó la caseína de soya del interior del conducto con conos de papel No. 35, No. 40 estériles y se realizó la inoculación de $20 \mu \mathrm{L}$ de la suspensión de C. albicans ATCC 60193 en el interior del conducto (Figuras 3 y 4). Las aperturas de acceso al conducto radicular se sellaron con motas de algodón estéril y cemento coltosol F (Coltene) (Figura 5). Las raíces inoculadas con el microorganismo se colocaron en viales estériles (Figura 6) sumergidas en $1 \mathrm{~mL}$ de agua destilada estéril para evitar la deshidratación del diente y se incubaron durante 72 horas a $37^{\circ} \mathrm{C}$.

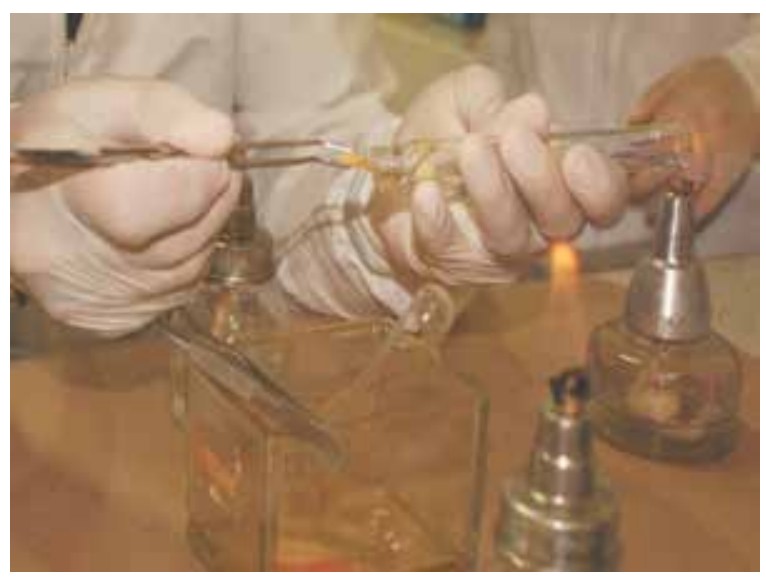

Figura 2. Retiro de la raíz del tubo de ensayo.

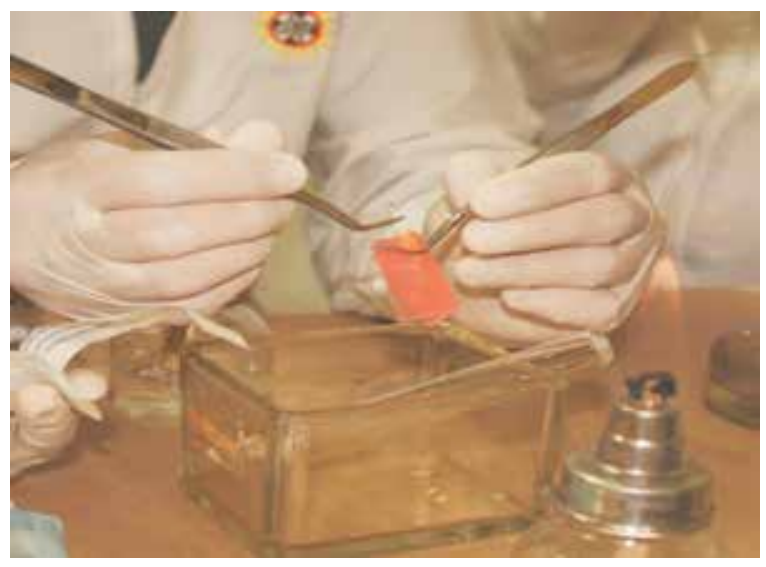

Figura 3. Secado del conducto con cono de papel No. 35. 


\section{ARTÍCULO DE INVESTIGACIÓN CIENTÍFICA Y TECNOLÓGICA}

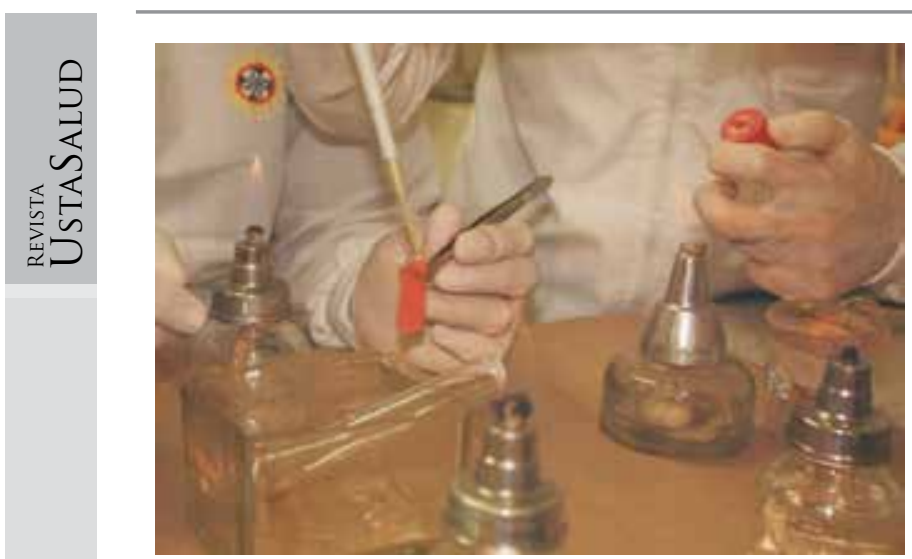

Figura 4. Inoculación de C. albicans, ATCC 60193.

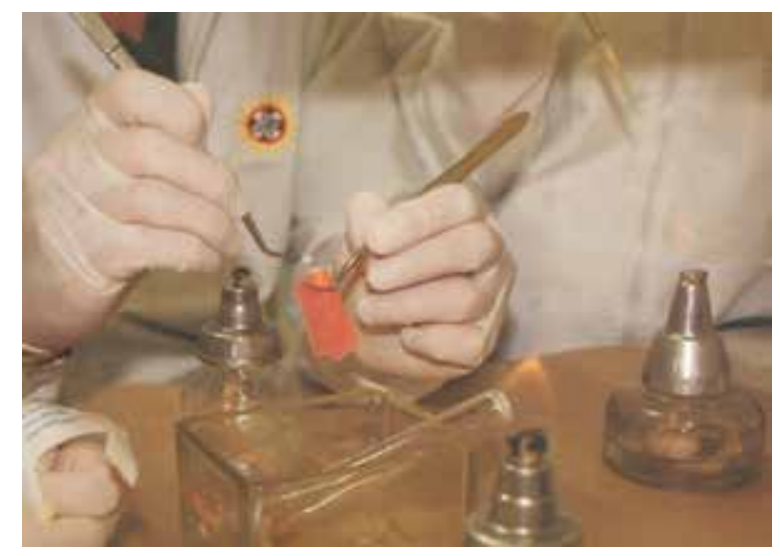

Figura 5. Sellado del acceso al conducto.

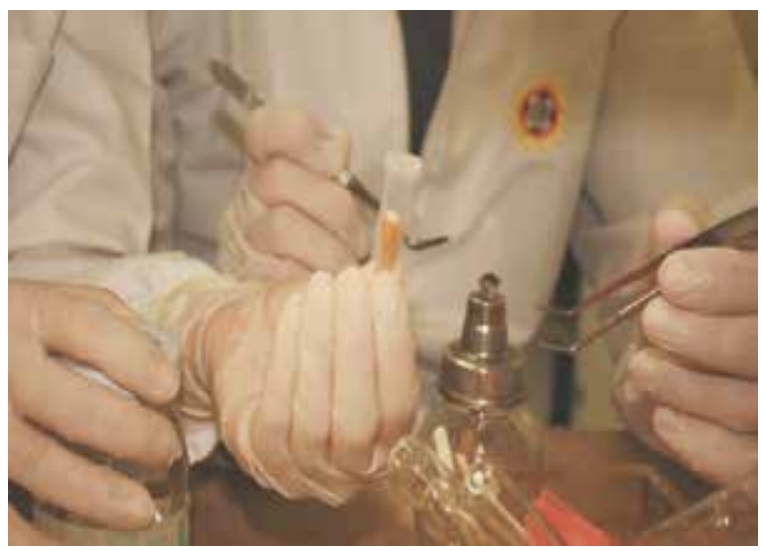

Figura 6. Raíz inoculada en vial estéril.

Asignación aleatoria de la medicación: luego del tiempo de inoculación y bajo un ambiente estéril (mecheros con alcohol industrial 98\%), con pinza se retiró la raíz del vial estéril, se envolvió en la parafina para su manipulación, se removió el sellado de coltosol F (Coltene) con una cucharilla y con el explorador se tomó la mota de algodón que fue llevada al agar Sabouraud $2 \%$ durante 48 horas a $37^{\circ} \mathrm{C}$, con la finalidad de verificar la contaminación de los conductos por C. albicans (Figura 7, 8 y 9). El inóculo fue retirado de los conductos radiculares mediante irrigación con $2 \mathrm{~mL}$ solución salina. Se secaron los conductos con conos de papel estériles No. 35 y 40.

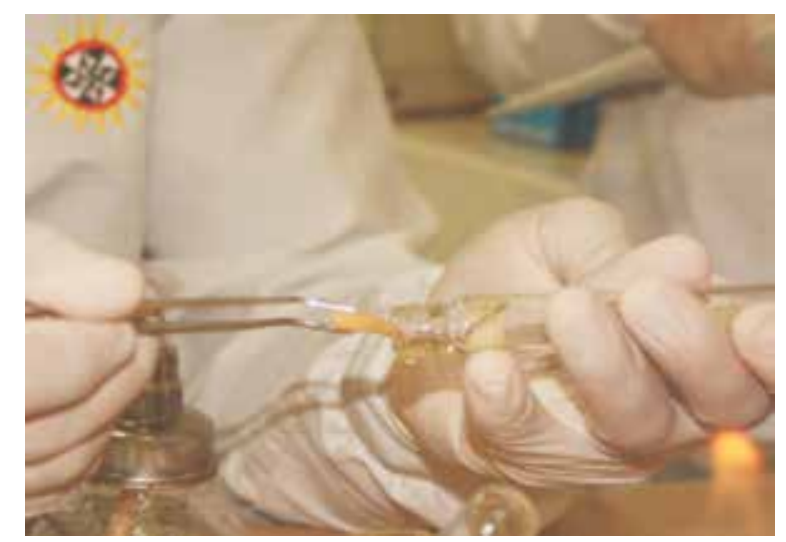

Figura 7. Retiro de la raíz del vial esteril.

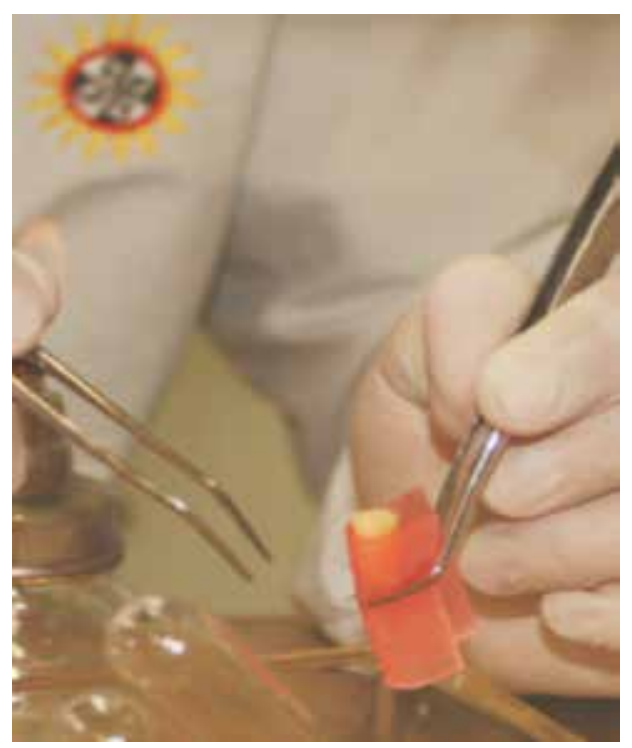

Figura 8. Cubrimiento con parafina.

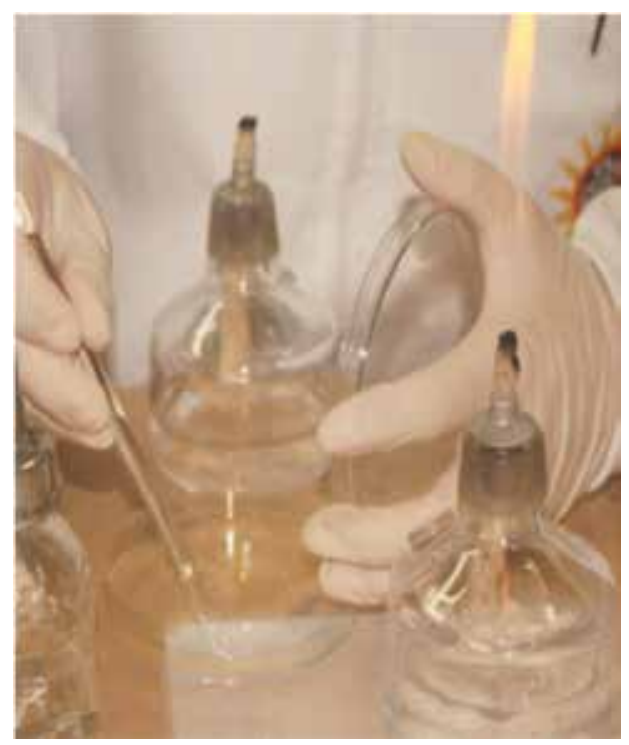

Figura 9. Mota de algodón en agar Saboraud. 
La asignación de raíces dentales para la medicación intraconducto se efectuó en forma aleatoria mediante el programa STATA Corp. Versión 9, que generó una lista de números aleatorios para formar los tres grupos de estudio. La medicación intraconducto se realizó de la siguiente manera:

- Tratamiento 1: digluconato de clorhexidina en gel al 2\% (Cleanform ${ }^{\circledR}$ ), se aplicó dentro del conducto radicular utilizando léntulo No. 40, para medicación intraconducto.

- Tratamiento 2: digluconato de clorhexidina al $0,2 \%\left(\right.$ Clarax $\left.^{\circledR}\right)$, se aplicó dentro del conducto radicular utilizando léntulo No. 40 , para medicación intraconducto.

- Tratamiento 3: solución salina (SSN) como grupo control, se aplicó mediante el uso de una jeringa (Endoject) y aguja calibre 27.

Una vez realizada la medicación intraconducto, se sellaron las raíces en su tercio cervical con coltosol $\mathrm{F}$ (Coltene) y se incubaron durante siete días a $37^{\circ} \mathrm{C}$ en viales estériles con $1 \mathrm{~mL}$ de agua destilada estéril.

Recolección de la muestra de dentina radicular: después de la terapia de medicación intraconducto, se retiró el diente del vial con pinza estéril, se colocó en una lámina de parafina sosteniéndolo con la mano para proceder a retirar el material temporal obturador en este caso el coltosol F (Coltene) con cucharilla, y la mota de algodón con el explorador.

Posteriormente se irrigó dos veces el conducto utilizando jeringa (Endoject) y solución salina. Se secó el conducto con puntas de papel estéril No. 35 y 40. La recolección de la muestra se realizó con lima tipo K No. 40 mediante el limado de las paredes del conducto. La lima que contenía el barrillo dentinario fue llevada a tubos que contenían 9,9 mL de solución salina estéril para la siembra en cajas de agar Sabouraud $2 \%$.

Luego de 48 horas, se realizó la comprobación de la efectividad de la medicación mediante el conteo de colonias de $C$. albicans que crecieron sobre la superficie del agar y se determinó según el método las $\mathrm{UFC} / \mathrm{mL}$ de $C$. albicans. Estas colonias de levadura se reconocieron por ser de aspecto blanco opaco cremoso, de diámetro entre 0,3 y $0,5 \mathrm{~mm}$, que al examen microscópico con azul de lactofenol se observan como blastoconidias elípticas y pseudohifas.

\section{RESULTADOS}

Fueron analizados un total de 48 dientes unirradiculares con un solo conducto, los cuales fueron distribuidos en tres grupos de tratamiento, cada uno con 16 dientes. El modelo de infección permitió establecer el crecimiento de $C$. albicans, en el interior del conducto en un $100 \%$ en las raíces de los dientes antes de su medicación.

Finalmente, al evaluar el efecto de la medicación intraconducto, se encontró que la mediana de las UFC en el grupo de digluconato de clorhexidina en gel al $2 \%$ fue de 2 , en el grupo de digluconato de clorhexidina en gel al 0,2\% fue de 1,5 y en el grupo control (Solución Salina al 0,9\%) fue de 65. En la Tabla 1 se muestran las diferentes medidas de tendencia central y dispersión calculadas para cada grupo.

Tabla 1. Descripción de los grupos de medicación intraconducto.

\begin{tabular}{|c|c|c|}
\hline Grupo (UFC/mL) & Estadístico & Valor \\
\hline \multirow[t]{9}{*}{ Clorhexidina $2 \%$} & Mediana & 2,00 \\
\hline & Varianza & 170,129 \\
\hline & Desv. Típ. & 13,04 \\
\hline & Mínimo & 0,00 \\
\hline & Máximo & 48,00 \\
\hline & Rango & 48,00 \\
\hline & Amplitud intercuartil & 5,00 \\
\hline & Asimetría & 2,74 \\
\hline & Curtosis & 7,35 \\
\hline \multirow[t]{9}{*}{ Clorhexidina $0,2 \%$} & Mediana & 1,50 \\
\hline & Varianza & 2238728,30 \\
\hline & Desv. Típ. & 496,24 \\
\hline & Mínimo & 0,00 \\
\hline & Máximo & 6000,00 \\
\hline & Rango & 6000,00 \\
\hline & Amplitud intercuartil & 5,50 \\
\hline & Asimetría & 3,98 \\
\hline & Curtosis & 15,90 \\
\hline \multirow[t]{9}{*}{ SSN $0,9 \%$} & Mediana & 65,00 \\
\hline & Varianza & 3179444,70 \\
\hline & Desv. Típ. & 783,10 \\
\hline & Mínimo & 1,00 \\
\hline & Máximo & 7200,00 \\
\hline & Rango & 7199,00 \\
\hline & Amplitud intercuartil & 77,75 \\
\hline & Asimetría & 3,98 \\
\hline & Curtosis & 15,89 \\
\hline
\end{tabular}

Por otra parte, se realizó la prueba de normalidad de Shapiro Wilk y se evidenció un valor de $p<0,05$ lo que demostró que los datos no distribuían normalmente. Por lo tanto, se usó la prueba no paramétrica de Kruskal-Wallis. Se encontró una diferencia estadísticamente significativa en las UFC/mL de los grupos de tratamiento $(p<0,0001)$. Posteriormente, se determinó cuáles grupos eran diferentes entre sí mediante el test de comparaciones múltiples de Dunn.

Se encontró que el grupo control (Solución Salina al $0,9 \%)$ presentó una diferencia estadísticamente significativa $(\mathrm{p}<0,0001)$ con respecto a los grupos de 
clorhexidina al $0,2 \%$ y $2 \%$. Sin embargo, la prueba U de Mann-Whitney evidenció que no hubo una diferencia estadísticamente significativa en las UFC/ $\mathrm{mL}$ del grupo tratado con clorhexidina al $0,2 \%$ y el grupo tratado con clorhexidina al $2 \%(\mathrm{p}=0,897)$ como medicación intraconducto. Luego se aplicó la prueba de $\mathrm{Chi}^{2}$ y se obtuvo un valor $\mathrm{p}=0,720$, que señaló que no hubo una diferencia estadísticamente significativa entre las dos concentraciones

\section{DISCUSIÓN}

La presencia de microorganismos y sus productos en un sistema de conducto radicular avascular y necrótico son los principales factores etiológicos de la periodontitis apical. ${ }^{10,16} \mathrm{~A}$ causa de las irregularidades de la anatomía del conducto radicular, las soluciones irrigantes antimicrobianas son utilizadas para ayudar en la etapa del control microbiano. ${ }^{10,17}$ Las ramificaciones apicales, conductos laterales e istmos permiten a Candida albicans protegerse de los efectos de la solución irrigante o medicamento intraconducto.

Kakehashi y colaboradores demostraron que las bacterias eran las responsables de la enfermedad pulpar, sin embargo, numerosos estudios han revelado un posible papel de los hongos en la incidencia de la infección endodóntica. La literatura revela que Enterococcus faecalis y Candida albicans fueron los microorganismos más prevalentes asociados con tratamientos endodónticos fallidos. ${ }^{18,19}$ Dentro del contexto de la enfermedad perirradicular Candida albicans representa la especie más comunmente aislada de conductos radiculares infectados. ${ }^{9,20,21}$

Los hongos poseen virulencia que se le atribuye a su capacidad de adaptarse a una gran diversidad de condiciones ambientales, adhesión a una variedad de superficies, producción de enzimas hidrolíticas, transición morfológica, formación de biofilm y evasión e inmunomodulación de las defensas del huésped, lo cual podría jugar un papel en la patogénesis de la enfermedad perirradicular., ${ }^{90}$

La medicación intraconducto más utilizada ha sido el hidróxido de calcio el cual efectivamente destruye gran parte de las bacterias del conducto radicular; ${ }^{22}$ no obstante, es menos efectivo contra Candida albicans. ${ }^{23,24}$

Waltimo y colaboradores evaluaron diferentes especies de candida incluyendo Candida albicans, en presencia de hidróxido de calcio In vitro y reportaron su resistencia a este medicamento. Concluyeron que era necesario utilizar agentes complementarios para tratar efectivamente la periodontitis apical persistente. ${ }^{25}$
Clínicamente, el hidróxido de calcio se usa con frecuencia como medicamento intraconducto, sin embargo $C$. albicans puede sobrevivir en los túbulos dentinales a pesar de largos períodos de terapia con él. ${ }^{23,26}$ Candida albicans fue más resistente al hidróxido de calcio que E. faecalis In vitro. ${ }^{26}$. Esta observación está de acuerdo con el trabajo realizado por Waltimo y colaboradores en el que sugieren que la clorhexidina fue más efectiva que el hidróxido de calcio al eliminar Candida albicans. ${ }^{23}$

La clorhexidina en gel mostró excelente actividad antimicrobiana frente a Candica albicans ${ }^{26}$ y los resultados fueron similares a los presentados por Ferguson y colaboradores quienes reportaron que cuando era mantenida en contacto directo con Candida albicans, la clorhexidina fue un agente antifúngico efectivo. ${ }^{27}$

El hecho de que los estudios epidemiológicos, constaten la asociación de Candida albicans con las infecciones endodónticas persistentes debido a sus excepcionales mecanismos de patogenicidad, fundamentó la necesidad de la evaluación de la eficacia de la medicación intraconducto frente a Candida albicans, en esta investigación. ${ }^{4,9,28}$

El método usado en este estudio fue tomado de Haapasalo y Orstavik con algunas modificaciones. ${ }^{6}$ Ellos realizaron la medicación intraconducto del digluconato de clorhexidina en gel al 0,2\% mediante jeringa y aguja calibre 27 . En esta investigación se realizó la modificación al llevar la medicación intraconducto del digluconato de clorhexidina en gel en ambas concentraciones $0,2 \%$ y $2 \%$, con léntulo número 40 , para tratar de simular el procedimiento clínico. $^{29}$

El modelo de este estudio In vitro permitió corroborar la capacidad de Candida albicans para colonizar el conducto radicular y los túbulos dentinales debido a que se evidenció crecimiento en todos los grupos después de tres días de su inoculación.

Los resultados de este estudio demostraron que el digluconato de clorhexidina en gel al $0,2 \%$ es efectivo para disminuir el crecimiento Candida albicans, a los siete días de medicación intraconducto. Estos hallazgos son similares con los de Vianna y colaboradores, quienes observaron una disminución en el crecimiento de colonias de Candida albicans. ${ }^{30} \mathrm{Sin}$ embargo, Paquette y colaboradores reportaron un moderado incremento de colonias en los conductos medicados con digluconato de clorhexidina al 0,2\% a los siete días de medicación intraconducto, ${ }^{24}$ al igual que Manzur y colaboradores quienes no observaron cambios en el recuento microbiano de conductos medicados por el mismo periodo de tiempo. ${ }^{7}$ 
En este estudio, la eficacia del digluconato de clorhexidina en gel al $0,2 \%$ fue del $37,5 \%$ y al $2 \%$ del $43,8 \%$ y dado que no se evidenció diferencia estadísticamente significativa, es posible sugerir que las dos concentraciones tienen propiedades antifúngicas para reducir la cantidad de UFC de Candida albicans. Esto concuerda con el estudio de Estrela y colaboradores quienes afirmaron que la Concentración Inhibitoria Mínima (MIC) del digluconato de clorhexidina en gel es de $0,02 \%$ frente a Candida albicans. ${ }^{31}$ Para Ferguson y colaboradores, el digluconato de clorhexidina en gel es un efectivo agente antifúngico en una MIC menor de 0,63 $\mu \mathrm{g} / \mathrm{mL}^{.27,28}$

Por consiguiente, se requieren más investigaciones para evaluar a profundidad el digluconato de clorhexidina en gel como medicamento intraconducto con el fin de lograr la eliminación completa de las unidades formadoras de colonias de Candida albicans.

\section{Conclusiones}

Candida albicans ATCC 60193, después de un periodo de incubación de 72 horas a $37{ }^{\circ} \mathrm{C}$ es capaz de colonizar en el interior del conducto radicular. En el análisis del barrillo dentinal obtenido mediante el limado de las paredes del conducto mostró afinidad y penetrabilidad por el tejido dentinario.

El digluconato de clorhexidina en gel al 0,2\% y $2 \%$, como medicación intraconducto, disminuye significativamente las UFC/mL de Candida albicans, pero no en su totalidad, después de siete días.

No se observó una diferencia estadísticamente significativa al comparar la eficacia del digluconato de clorhexidina en gel al $0,2 \%$ y al $2 \%$ lo que indica que luego del experimento In vitro ambas concentraciones disminuyen las UFC/mL de Candida albicans.

\section{BIBLIOGRAFÍA}

1. Baumgartner JC, Watts CM, Xia T. Occurrence of Candida albicans in infections of endodontic origin. J Endod. 2000; 26 (12): 695 - 698.

2. Sen BH, Piskin B, Demirci T. Observation of bacteria and fungi in infected root canals and dentinal tubules by SEM. Endod Dent Traumatol. 1995; 11 (1): 6 - 9.

3. Sen BH, Safavi KE, Spångberg LS. Antifungal effects of sodium hypochlorite and chlorhexidine in root canals. J Endod. 1999; 25 (4): 235 - 238.

4. Waltimo TM, Ørstavik D, Sirén EK, Haapasalo MP. In vitro yeast infection of human dentin. J Endod. 2000; 26 (4): $207-209$.

5. Nair PN, Sjögren U, Krey G, Kahnberg KE, Sundqvist G. Intraradicular bacteria and fungi in root-filled, asymptomatic human teeth with therapy-resistant periapical lesions: a long-term light and electron microscopic followup study. J Endod. 1990; 16 (12): 580 - 588.
6. Haapasalo M, Orstavik D. In vitro infection and disinfection of dentinal tubules. J Dent Res. 1987; 66 (8): 1375 $-1379$.

7. Manzur A, González AM, Pozos A, Silva-Herzog D, Friedman S. Bacterial quantification in teeth with apical periodontitis related to instrumentation and different intracanal medications: a randomized clinical trial. J Endod. 2007; 33 (2): $114-118$.

8. Barbosa CA, Gonçalves RB, Siqueira JF Jr, De Uzeda M. Evaluation of the antibacterial activities of calcium hydroxide, chlorhexidine, and camphorated paramonochlorophenol as intracanal medicament. A clinical and laboratory study. J Endod. 1997; 23 (5): 297 - 300.

9. Siqueira JF, Sen BH. Fungi in endodontic infections. Oral Surg Oral Med Oral Pathol Oral Radiol Endod. 2004; 97 (5): $632-641$.

10. Del Carpio-Perochena AE, Bramante CM, Duarte MAH, Cavenago BC, Villas-Boas MH, Graeff MS, et al. Biofilm dissolution and cleaning ability of different irrigant solutions on intraorally infected dentin. J Endod. 2011; 37 (8): $1134-1138$.

11. El Moug T, Rogers DT, Furr JR, el-Falaha BM, Russell AD. Antiseptic-induced changes in the cell surface of a chlorhexidine-sensitive and a chlorhexidine-resistant strain of Providencia stuartii. J Antimicrob Chemother. 1985; 16 (6): $685-689$.

12. McDonnell G, Russell AD. Antiseptics and disinfectants: activity, action, and resistance. Clin Microbiol Rev. 1999; 12 (1): $147-179$.

13. Parsons GJ, Patterson SS, Miller CH, Katz S, Kafrawy AH, Newton CW. Uptake and release of chlorhexidine by bovine pulp and dentin specimens and their subsequent acquisition of antibacterial properties. Oral Surg Oral Med Oral Pathol. 1980; 49 (5): 455 - 459.

14. Tervit C, Paquette L, Torneck CD, Basrani B, Friedman S. Proportion of healed teeth with apical periodontitis medicated with two percent chlorhexidine gluconate liquid: a case-series study. J Endod. 2009; 35 (9): 1182 - 1185.

15. Ferraz CC, Gomes BP, Zaia AA, Teixeira FB, Souza-Filho FJ. In vitro assessment of the antimicrobial action and the mechanical ability of chlorhexidine gel as an endodontic irrigant. J Endod. 2001; 27 (7): 452 - 455.

16. Ricucci D, Siqueira JF Jr. Biofilms and apical periodontitis: study of prevalence and association with clinical and histopathologic findings. J Endod. 2010; 36 (8): 1277 1288.

17. Susin L, Liu Y, Yoon JC, Parente JM, Loushine RJ, Ricucci $\mathrm{D}$, et al. Canal and isthmus debridement efficacies of two irrigant agitation techniques in a closed system. Int Endod J. 2010; 43 (12): 1077 - 1090.

18. Rôças IN, Hülsmann M, Siqueira JF Jr. Microorganisms in root canal-treated teeth from a German population. J Endod. 2008; 34 (8): 926 - 931.

19. Chandra SS, Miglani R, Srinivasan MR, Indira R. Antifungal efficacy of $5.25 \%$ sodium hypochlorite, $2 \%$ chlorhexidine gluconate, and 17\% EDTA with and without an antifungal agent. J Endod. 2010; 36 (4): 675 - 678.

20. Waltimo TMT, Sen BH, Meurman JH, Ørstavik D, Haapasalo MPP. Yeasts in apical periodontitis. Crit Rev Oral Biol Med Off Publ Am Assoc Oral Biol. 2003;14 (2): 128 - 137.

21. Sunde PT, Olsen I, Debelian GJ, Tronstad L. Microbiota of periapical lesions refractory to endodontic therapy. J Endod. 2002; 28 (4): $304-310$. 
22. Bystrom A, Claesson R, Sundqvist $G$. The antibacterial effect of camphorated paramonochlorophenol, camphorated phenol and calcium hydroxide in the treatment of infected root canals. Endod Dent Traumatol. 1985; 1 (5): $170-175$.

23. Waltimo TM, Orstavik D, Sirén EK, Haapasalo MP. In vitro susceptibility of Candida albicans to four disinfectants and their combinations. Int Endod J. 1999; 32 (6): 421 429.

24. Paquette L, Legner M, Fillery E, Friedman S. Antibacterial Efficacy of Chlorhexidine Gluconate Intracanal Medication In vivo. J Endod. 2007; 33 (7): 788 - 795.

25. Waltimo TM, Sirén EK, Orstavik D, Haapasalo MP. Susceptibility of oral Candida species to calcium hydroxide In vitro. Int Endod J. 1999; 32 (2): 94 - 98.

26. Ercan E, Dalli M, Dülgergil ÇT. In vitro assessment of the effectiveness of chlorhexidine gel and calcium hydroxide paste with chlorhexidine against Enterococcus faecalis and Candida albicans. Oral Surg Oral Med Oral Pathol Oral Radiol Endod. 2006; 102 (2): e27 - e31.

27. Ferguson JW, Hatton JF, Gillespie MJ. Effectiveness of intracanal irrigants and medications against the yeast Candida albicans. J Endod. 2002; 28 (2): 68 - 71.

28. Waltimo TMT, Haapasalo M, Zehnder M, Meyer J. Clinical aspects related to endodontic yeast infections. Endod Top. 2004; 9 (1): 66 - 78.

29. Wuerch RMW, Apicella MJ, Mines P, Yancich PJ, Pashley DH. Effect of $2 \%$ chlorhexidine gel as an intracanal medication on the apical seal of the root-canal system. J Endod. 2004; 30 (11): 788 - 791.

30. Vianna ME, Gomes BPF, Berber VB, Zaia AA, Ferraz CCR, de Souza-Filho FJ. In vitro evaluation of the antimicrobial activity of chlorhexidine and sodium hypochlorite. Oral Surg Oral Med Oral Pathol Oral Radiol Endod. 2004; 97 (1): $79-84$.

31. Estrela CRA, Estrela C, Reis C, Bammann LL, Pécora JD. Control of microorganisms In vitro by endodontic irrigants. Braz Dent J. 2003; 14 (3): 187 - 192.

Correos electrónicos de los autores:

Martha Patricia Verjel Bonza: marpaver@hotmail.com Vanesa Martínez Chacón:vanesamch@hotmail.com Beatriz Estella Duarte Pérez: bedupe78@hotmail.com Laura Viviana Herrera Sandoval: l.vivianaherrera@gmail.com Martha Elena Varón Plata: mevaron@gmail.com Anderson Bermón Angarita: andebermon@gmail.com Luis Jesús Cantillo Silva: luijecantillo@hotmail.com
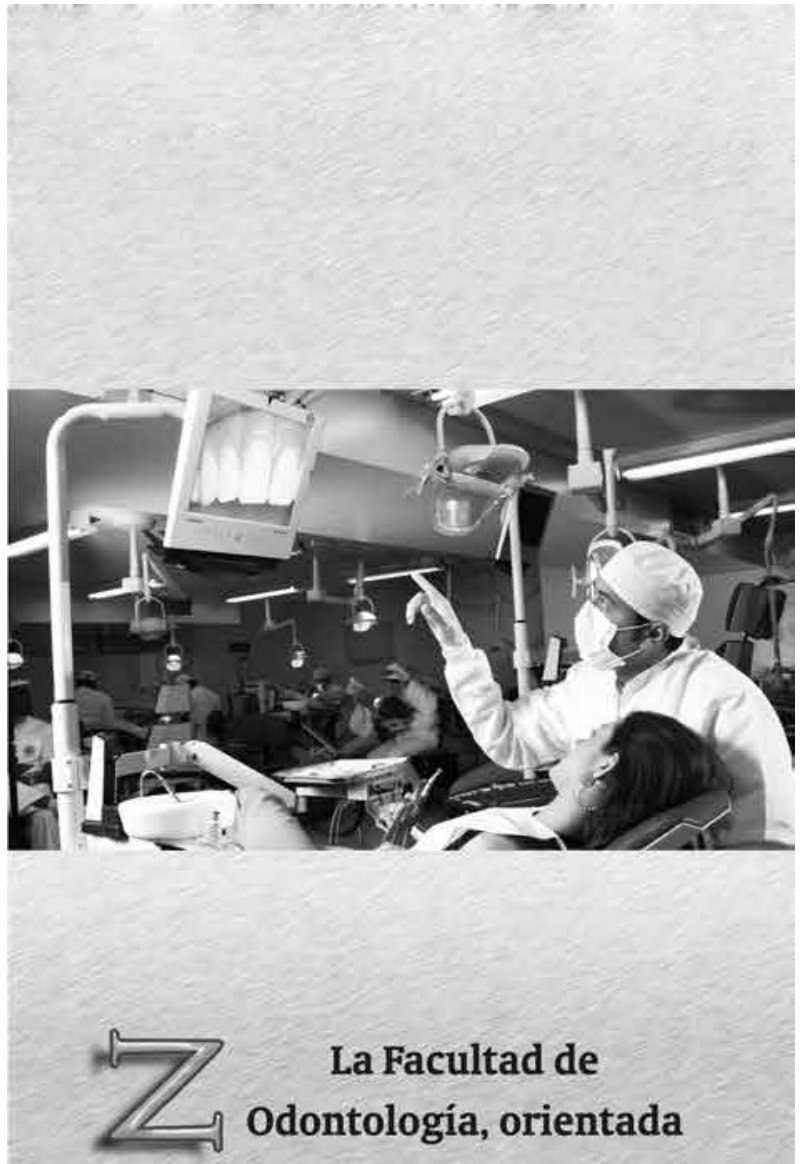

La Facultad de Odontología, orientada por el pensamiento de Santo Tomás, pretende

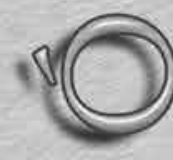
formar Odontólogos integrales $\mathrm{y} / \mathrm{o}$ especialistas a través de parámetros humanísticos, éticos, científicos, biotecnológicos, investigativos $\mathrm{y}$

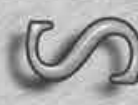

sociales, como recurso

humano capaz de

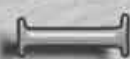

intervenir con éxito en

el proceso dinámico de la salud y la enfermedad, en el individuo, la familia y la comunidad. 